\title{
Eliciting stakeholder preferences on the potential benefit of diversified small-scale fishery activities
}

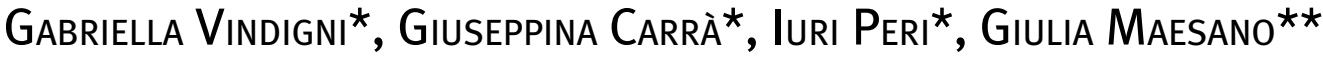

DOI: $10.30682 / \mathrm{nm} 2003 \mathrm{c}$

JEL codes: O12, O13, Q13

\begin{abstract}
This paper examines stakeholders' preferences concerning diversification of small scale fishery activities, which has become a necessity for many small-scale fishermen in order to provide additional sources of income, as their income is often inadequate. It's looks at participatory modelling as a potential tool to enhance mutual understanding and legitimacy. Fisheries stakeholders and those with an indirect interest in diversification of their activities were invited to participate in the process of framing the management problem and to give input and evaluate the scientific models that are used to provide suggestions to decision makers. We followed a number of different strategies to investigate the role of participatory knowledge development. The study empirically integrates the traditional models of multicriteria decision aid approach with the deliberative mapping perspective. We conclude that participatory modelling has the potential to facilitate and structure the deliberative process within a dialogue between scientists and stakeholders about uncertainties and the quality of the knowledge base. It can also contribute to collective learning, increase legitimacy, and advance scientific understanding.
\end{abstract}

Keywords: Cognitive maps, Diversification fishery activities, Multicriteria Decision Aid, Participatory approach.

\section{Introduction}

As a response to mitigate declines in catches and to support fishing communities facing changing conditions, the Common Fisheries Policy (CFP) incorporates a more significant social dimension, especially encouraging job creation and diversification into other activities in the marine environment. In this framework, sustainable fishery diversification is promoted for reducing the dependence on resources and conserving fish stocks through incentives for alternative or complementary activities. The European Maritime and Fisheries Fund (EMFF) 2014-2020 enhances this integrated territorial bottom-up strategy by applying the approach of Community-Led Local Development (CLLD) as a common and shared concept of all European Structural and Investment Funds (ESIF) for that period. The EMFF supports the implementation of the EU 2020 strategy. Therefore, the imple-

\footnotetext{
* Department of Agriculture, Food and Environmental, University of Catania, Italy.

** Consiglio per la ricerca in agricoltura e l'analisi dell'economia agraria, Centro di ricerca Politiche e Bio-economia, Roma, Italy.

Corresponding author: vindigni@unict.it
} 
mentation of CLLD must be as decentralized as possible, using a bottom-up approach to help fishing communities to adopt sustainable fishing practices and diversify income-generating activities which promote quality livelihoods.

The inherent complexity of socio-economic and environmental processes, such as the complexity of fishery community development, and the importance of stakeholder involvement in these processes is well-established in the literature (Munda, 2004; Haapasaari et al., 2013; Rey-Valette et al., 2017). The call for better participation mechanisms emerged for two main reasons: first, the normative reason, which argues that the benefits for a democratic society and equity are crucial; second, the pragmatic reason, which states that participation improves the quality and sustainability of decisions. Researchers tend to use participation for pragmatic reasons, whereas in participatory development, normative argument has been more prominent. In either way, the benefits to participation are apparent. Participation develops local trust, improves a program's efficiency and supports the theory that complex socio-environmental problems must be met with diverse knowledge, values, and ideas.

The framework of our research was inspired by the post-normal science approach, developed by Funtowicz and Ravetz (1993) at the beginning of the 1990s. These authors argue for including grassroots stakeholders as scientific peers and for integrating their diverse perspectives into the scientific analysis. They suggest that it is not possible rely only on text book knowledge and on the conclusions of so-called experts, because of the complexity of the interactions and the differential impacts on stakeholders. Therefore, it is recommended to involve an "extended peer community," consisting of all those affected by and willing to discuss the issue at hand. This approach combines analytical-descriptive and social aspects linking scientific problems with societal concerns. It is considered transdisciplinary, as it integrates scientific and extra-scientific expertise from relevant stakeholders' communities.

This "extended peer community" approach is reflected in the evolution of CFP, in which the role of stakeholders has evolved "from a traditionally linear science-policy interface towards a more interactive governance system that involves actors beyond scientists and policy makers" (Linke et al., 2011). The concrete implementation of the CFP objectives in the new policy processes could be better achieved through involvement of a broad range of civil society stakeholders (Jahn et al., 2012; Ziman, 1996).

This paper is based on the DiverSo project (DIVERsification of fishery activities \& Sustainability in the Jonian coastal area of Sicily), promoted by the Department of Fisheries of the Sicilian Region. Diversification activities assume a central role for the fishermen and their families, which are faced with the decline of fishing activities as consequence of stock depletion. Economic benefits for small-scale fishermen come from the increase of the number of income sources, generating financial resources that encourage them to keep practicing fishing. A participatory approach to assist the fishery community to undertake diversification activities has been chosen to support regional authorities for implementation of the new 2014-2020 programming period in the fisheries sector. The project was aimed at individuating the social acceptability and stakeholders' preferences of diversified fishery activities, to ensure that local communities fully take advantage of the opportunities offered by maritime and coastal development in the new programming period. Widespread stakeholder participation was solicited to increase the transparency of the complex decision-making process, mitigate conflicting interests and improve the relevance of the outcomes. The process applies cognitive strategic thinking to a public policy problem in order to integrate and explicate multiple decision-makers' subjective understandings of the problem in a cognitive map; individuate different actions in the context of diversification fisheries policy, and provide foresight or forward-looking impact assessment in terms of actions' clusters.

The implementation of the fishery diversification activities is complex in terms of both the disparate stakeholders and the social dimensions to be considered. Policy issues must be analysed within the social context in which they occur. In the case of the involvement of multiple decision-makers or groups of stakeholders with conflicting interests, 
an integrated methodology is considered beneficial. This methodology requires flexible and versatile decision-making processes instead of "traditional" simulation and optimization tools.

Therefore, we first performed participative workshops with stakeholders and experts who were representative all groups with a vested interest in fishery diversification. The purpose of these discussions was to promote an exchange of ideas among participants and to brainstorm actions to be implemented. Then, cognitive maps were co-constructed to configure the different perceptions of groups of participants by mapping concepts and possible causal links (Kpoumié et al., 2017). After converting these cognitive maps into a value tree, the AHP (Analytical Hierarchical Process) method was implemented in order to structure ideas, criteria and objectives of the actors hierarchically to create a shared vision of sustainable strategic actions for policy makers.

\section{Theoretical background}

Emerging trends, such as the increasing demand for participation in the policy making process, mistrust between citizens and policy makers, social fragmentation, exponential increase in citizens' access to information, and the lack of regulation on the reliability and truthfulness of that information, have created the need to use tools of evaluation to meet the nature of policy makers' demands. Given the complexity of the implementation of EU fishery diversification opportunities, we adopted a multi-methodological framework based on multi-criteria decision aiding (MCDA). Decision support systems of sustainable local fisheries often use this method. Belton and Stewart (2002) define MCDA as "an umbrella term to describe a collection of formal approaches, which seek to take explicit account of multiple criteria in helping individuals or groups to explore decisions that matter."

MCDA emphasizes the idea of problem construction, focusing on the modelling of the decisional context, starting from the beliefs and values of the actors implicated in the decision-making process. This is used to construct the most appropriate decision-making model for a given context
(Roy, 1990). MCDA transcends traditional Operational Research (OR), which analyses only one criterion, by using normative mathematical models to find an optimal solution. At the end of the 1960s, new methods emerged to support the decision-making process for complex problems, the so-called "soft approaches." Complex problems are characterized by non-optimal situations in which the need for data is reduced, situations are simple and transparent, people are active elements of the decision-making process, and uncertainty is accepted (Ferreira et al., 2011). The need to deal with a growing diversity of new and conflicting interests has favoured the acceptance of systemic approaches with the use of multiple criteria (Roy, 1985). However, there are no features inherent in classical MCDA, which capture the values of multiple decision makers or consider social uncertainty in public policy decisions. Therefore, the problem must be adequately structured for the analysis to be successful.

Over the years, many scholars have recognized the importance of adequate problem structuring to reach favourable outcomes in analytical decision support interventions. Most of them have relied on impromptu problem structuring practices. The use of a formal methodology for identifying the key variables and interactions in a complex problem situation may enhance problem structuring and system dynamics modelling. PSMs (Problem Structuring Methods) are now widely accepted decision analytic tools and there is an emerging body of research and practice on the integration of such methods with other formal and/or quantitative methods (Tsoukias et al., 2013). PSMs deal with unstructured problems characterized by the existence of multiple actors with divergent perspectives and disparate, and/or conflicting interests (Rosenhead and Mingers, 2001). The methods of PSM rely heavily on the participation of stakeholders in the decision making process and often employ qualitative models (Franco and Montibeller, 2010).

One of the most used tools is the cognitive map that creates a visual representation of how participants think about a particular issue by analysing and arranging the problems, identifying causes and effects, explaining causal links and diagram- 
ming how concepts relate to each other (Eden and Ackermann, 1992; Bryson et al., 1995).

The theory, based in cognitive psychology, Kelly $(1955,1970)$ argues that human beings are problem finders/problems solvers, continually striving "to make sense" of their world in order to "manage and control" that world. By identifying the causal links of a problem, actions are guided by logic rather than emotion. Understanding how individuals or group members perceive a situation is fundamental, as it is this that influences actions. Checkland (1978) calls this approach of thinking of systems as mental constructs to help individuals make sense of problematic situations "soft systems thinking."

Tsoukias et al. (2013) introduced a new category of decision analytics labelled "Policy Analytics" which aim to support policy makers in a meaningful, operational and legitimating way. Decision analysts combine a wide range of existing data and knowledge with a constructive approach to surfacing, modelling and understanding the opinions, values and judgments of the stakeholders involved. The term "Policy Analytics" refers to the development and application of the necessary skills, methodologies, methods and technologies, needed to engage relevant stakeholders in policymaking in a meaningful and reflective way. In light of this, we incorporated other decision support systems into the multi-criteria methodology to create a single paradigm - the learning paradigm - to ensure the process is consistent and theoretically and practically cohesive (Midgley, 1997).

The study was carried out in the context of a transdisciplinary project on diversification of fishery activities and sustainability in the Ionian coastal area of Sicily. In that area, over the years, small-scale fisheries have contributed to the improvement of the standard of human life and to the equilibrium between environment and local development. Nowadays, the anthropic pressure, a consequence of the urbanization phenomenon affecting the coast, has caused a loss of biodiversity and habitat degradation. From an economic point of view, the area has experienced a steady decline in fishing catches and the increase in production costs, reflecting the overall Mediterranean trend.
Despite the opportunities in EU programming CFP and plenty of examples of successful diversification initiatives, the interest in fishery diversification in our area of study is notably limited. Diversification is constrained by several factors. Small-scale fisheries communities are often marginalized in local development planning, as they are often considered difficult to work with due to poverty, low capacity and lack of skills. Sectorial interventions focused on diversification may be limited by weak linkages and poor coordination. Lack of capabilities and experience within institutions has limited the efficacy of local initiatives in addressing complex issues such as resource management and livelihoods development.

\section{Methodology}

\subsection{The context for small-scale fishery diversification strategies}

The study area overlooks the Mediterranean basin laying in the eastern coast of Sicily (Jonian sea). It covers more than $160 \mathrm{~km}$ from North (Giardini Naxos - Messina) to South (Portopalo-Syracuse) (Figure 1).

The coastal shelf is characterized by great environmental heterogeneity and a high degree of biological productivity. The presence of two marine protected areas ("Cyclops Island" and "Plemmirio") and several natural reserves (Fiumefreddo, Timpa of Acireale, Simeto Oasis, Vendicari) positively affects the biological richness of the area.

The small-scale fisheries characteristics in the study area concerned are in line with those of the fisheries in the whole Sicily.

The large number of fishing methods employed in relation to the different sea bottoms and currents as well as the seasonality is adapted to variety of fish populations to optimize the catches. Therefore, the majority of the catches are taken through a multi-purpose fishing systems, which provide a wide set of catches such as tuna, swordfish, oily fish and shellfish.

Over the past decade the evolution of Sicilian fishery sector shows a steady decrease following the path of the general decline at national level. 


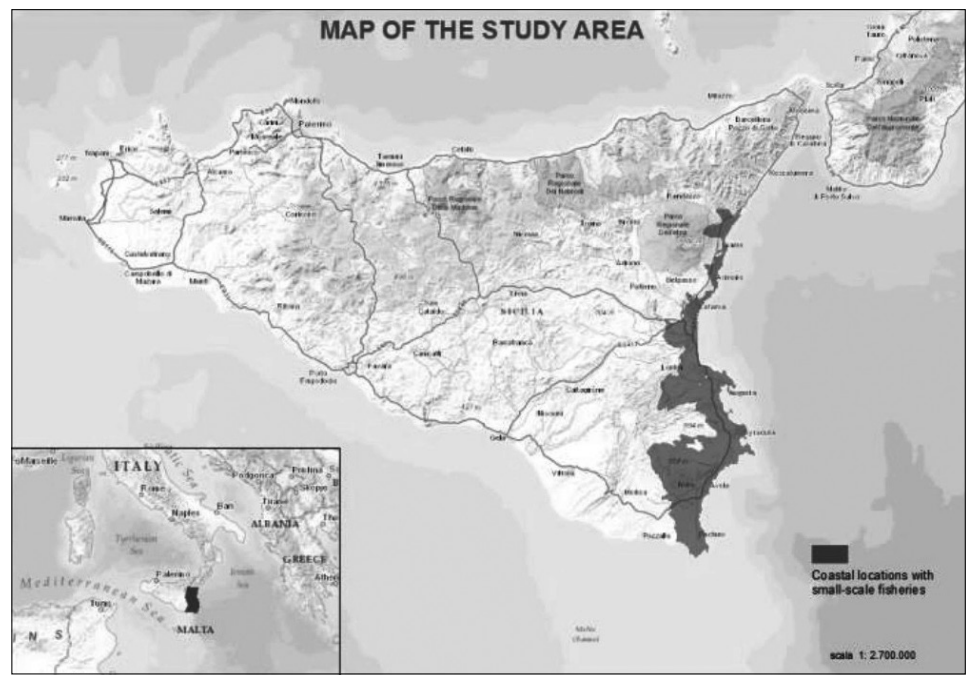

Figure 1 - The study area.

\subsection{Problem structuring, stakeholder selection and deliberative process}

The structuring process was carried out trying to reconcile the "technocratic" and "citizen-centric" approaches. As mentioned above, the appraisal of different options fails to engage the knowledge, values and interests of stakeholders with those of wider society.

In our project the deliberative process has been divided into two stages: the first one for "expert" - project coordinator and the team responsible for the project, with acknowledged expertise in the issue under discussion - the second for "stakeholders" - fishers as well as those with an involvement in the fisheries diversification. Therefore, the structuring of the decision problem was based on a facilitated discussion between an expert and groups of stakeholders, which allowed us to construct a shared vision and social acceptability of actions aiming at diversifying fishery activities in the eastern coastal area of Sicily which has been affected by the decline in fishing production. Stakeholders' perspectives helped us to supplement our scientific information by improving local economic, environmental and social knowledge and revealing new information to the local decision makers (Wiber et al., 2004; Linke et al., 2011; Röckmann et al., 2012; Haapasaari et al., 2013; Degnbol et al., 2006; de Vos and Tatenhove, 2011).
A preliminary inventory of existing local practices of diversification and their potential for development was carried out (Carrà et al., 2014). Questionnaires were used to secure baseline knowledge on the local diversification of fishery activities and their spatial distribution. They were administered through face-to-face interviews with individuals actively engaged in small scale fishing activities, as well as participative workshops discussions with key stakeholders in the areas of study. This preliminary analysis highlighted the different types of fishery diversification activities practiced in the Ionian coast, together with their spatial location and prevalence. At the same time a wide range of potential actions was identified, such as those with the possibility to improve production, increase technical and economic efficiency, improve product quality, enable better market access, and other activities such as micro-enterprises that can have a positive or neutral effect on fishery resources.

The different types of diversification were subsequently classified into three categories: (i) the field of tourism (such as fishing tourism, sport tourism, itti-tourism, pleasure fishing); (ii) the field of products processing and selling (fish processing, local tastings, direct selling to consumers and fishmongers); (iii) and the field of eco-activities (such as environmental monitoring, waste collecting, monitoring of the sea environment). 
All this information was used by the expert team to select in advance a set of options, and to provide a central focus of the discussion during the assessment with participants. However, participants were allowed to freely develop their own appraisal on additional options that were significant to them. These yielded important information on the perspectives of individual participants and allowed us to check for the completeness and relevance of predefined options.

The fishery diversification activities identified on the basis of the above analysis have been appraised according to the perception of relevant stakeholder identified (Aanesen et al., 2014). These encompass fishermen (owners of multi-use vessels less than 12 metres in length) with a direct interest in fisheries diversification and all those with a less direct interest, but with a pertinent perspective on the policy options relevant to that issue, such as stakeholders operating within the food chain, professionals, service providers in both the public and private sectors. All those were recruited as individuals or as representatives of associations or institutional affiliations.
The development of diversification fishing activities depends to a crucial extent on a multiplicity of stakeholders. A special role is played by the Fisheries Local Action Groups (FLAGs), in which those working in the fisheries sector and other local public and private stakeholders together devise and implement a bottom-up strategy geared to the economic, social, and environmental needs of the area concerned.

After a preliminary consultation, stakeholders involved were grouped to address diverse perspectives as shown in the Figure 2. This classification is not clear-cut since many activities fall into more than one category, because of their integrated or multi-sectoral activities.

Stakeholders were recruited to join each of the four participative workshops to gather information from a diverse set of stakeholders. The recruitment process was well adapted to the different circumstances. Stakeholders were contacted initially by telephone, but in some instances it was more feasible to visit them as this was considered to be beneficial in developing contacts for the later stages of research.

We conducted four participative workshops in different locations along the Jonian coast,

Figure 2 - Relevant categories of stakeholders.

\begin{tabular}{|ll|}
\hline Perspectives of stakeholders & Categories \\
\hline Fishermen & - individual fishers \\
& - producer organizations \& cooperatives \\
\hline Fish processing industry & - local fishermen associations \\
\hline Public control \& management & - sea food industry, dryers, smokers, freezers, canneries \\
& - local gastronomy \& restaurants \\
\hline Recreationist & - coast guard \\
& - border inspection and surveillance \\
\hline Academics and civil society & - fish restaurant \& culinary heritage operators \\
& - tourist associations \\
\hline Retailers & - pescatourism, ittitourism, angling, diving associations \\
\hline & - Fisheries Local Action Groups (FLAGs) \\
& - university and research institutions \\
\hline
\end{tabular}

Source: our elaboration. 
Figure 3 - Structure of the analytic process.

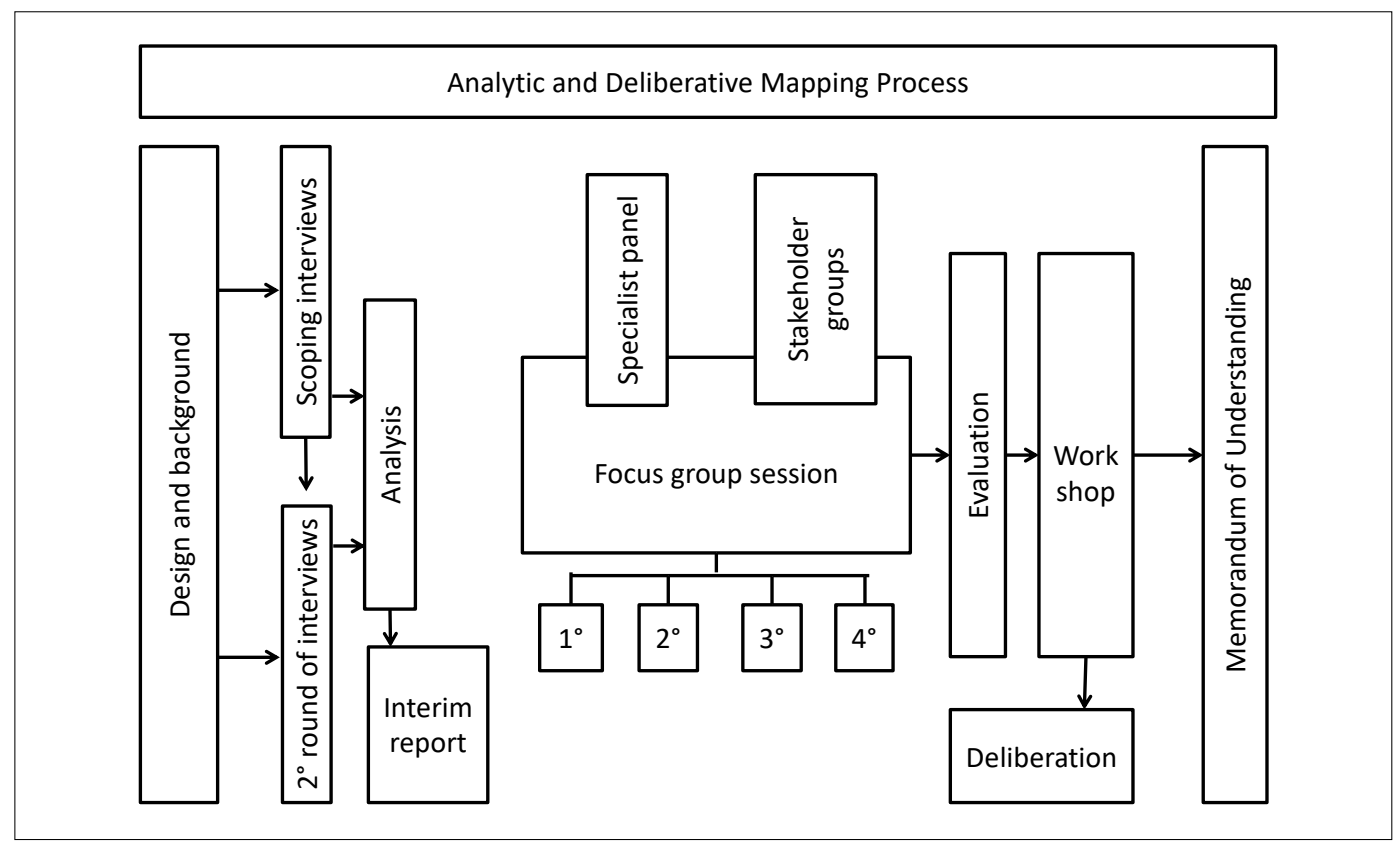

Source: our elaboration.

chosen according to their specific characteristic: Riposto (number of stakeholders: 55) and Portopalo (number of stakeholders: 45) for the relevant number of small fishery activities and importance of fish production and processing; two Marine protected areas (AMP), namely Ciclopi (number of stakeholders: 27) and Plemmirio (number of stakeholders: 38), for their relevance in terms of environmental value, which has generated several touristic economic opportunities. The relevant number of people recruited allowed us to gather significant information about peoples' views and the distribution/range of relevant perspectives.

Each participative workshop started with a presentation by an expert of the DiverSo project team, which introduced the relevance of fishery diversification, the activities already undertaken in Sicily and the new funding opportunities offered in the framework of the new operational Program of the EMFF. Then participants were invited to form smaller discussion groups (8-12 participants) on specific sub-topics regarding alternative available perspectives, allowing their own views to be developed and challenged. Participants in the smaller facilitated groups took turns to ensure that all of them had a say in each topic in place. Each small group was supported by a member of the expert team who facilitated group discussions, promoted the exchange of ideas, ensured all points of view were heard and offered suggestions and opinions. The facilitator allowed groups to frame their discussion in public terms, and to reframe problems in case of conflict. Disagreement was a part of the deliberative process, but participants negotiated and iterated their conflict according to the way they framed the issue and their relationships. This is an important process in making sense of an issue and understanding relationships. The results of facilitated discussion were translated into participatory maps. Despite the diversity of perspectives, the results of process were remarkably consistent across the groups of stakeholders and experts.

A final workshop provided participants with the opportunity to have a greater understanding to reach an informed position.

The structure of the analytic and deliberative process is illustrated in Figure 3. 


\subsection{Stakeholders' preference in assessing benefit of fishery diversification}

In order to explore perspectives of the individuals engaged in such activities, participants have been invited to participate in open discussion and focus groups. The participatory research process took place from 2014 to 2015. This process has been carried out through eight main workshops, which were attended by $15-20$ stakeholders each, and 3 smaller focus group on selected topics. The technique of cognitive map was used to work with groups of actors, experts and stakeholders active in local coastal areas. By groups open-discussions on major challenges and concerns, each participant was asked to express fundamental point of view and concerns that could improve the adoption of diversification strategies.

In order to highlight key factors of fishery diversification activities, each participative workshop co-constructed a cognitive map with the help of the facilitator (Ackermann and Eden, 2004; Bryson et al., 2004). Related concepts were placed as close together as possible to create an appealing display. To this end, the same understanding of the problem was shared through several rounds of discussion with participants. A graphic representation of key points of discussion was synthesized to form a comprehensive vision of the problem of diversification.

We used facilities provided by Decision Explorer to analyse and identify key issues. Cluster analysis, using the parameters of the target and the minimum size of the cluster, was used to identify key issues by synthesizing and analysing the data.

During the workshop, facilitators reviewed and compared individual evaluations and maps, identified key similarities in concepts, and merged all concepts from the individual maps into an aggregated map displayed in Figure 4, and to help in the formulation of a consensus on the next steps in the process (Hodgkin et al., 2005; Eden and Ackermann, 1998).

In this way, in the framework of multi-criteria-analysis, decision-support methods enabled us to capture the perspectives of each stakeholders' group. The elicitation process was framed as an exercise to expand upon previous appraisals to increase the range of options.

Interviewees were free to define options that are significant to them to foster diversification

Figure 4 - Aggregate Cognitive Map.

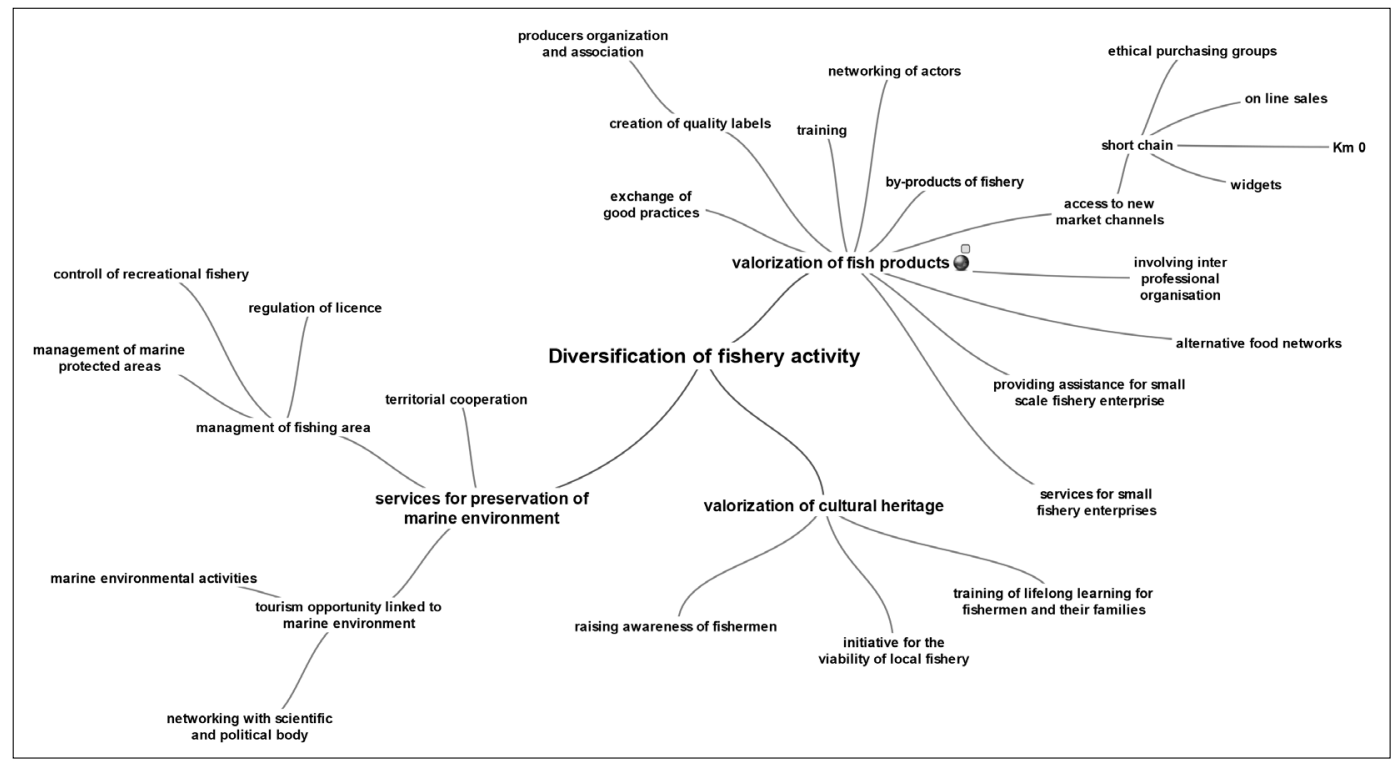

Source: our elaboration. 
Figure 5 - Hierarchical tree.

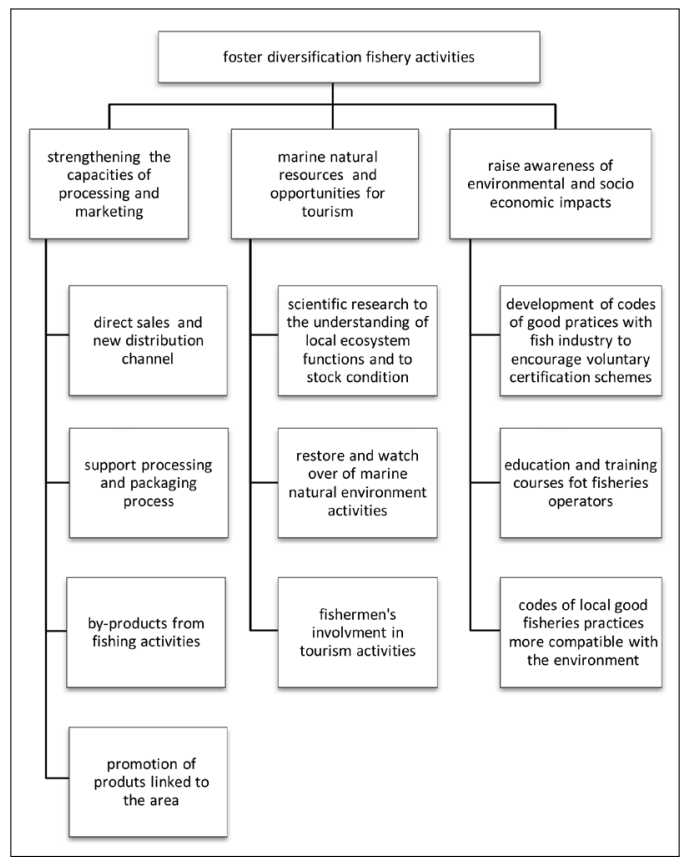

Source: our elaboration.

strategies that they feel are most appropriate in their context. The research team analysed their statements in order to identify primary assessment elements that the actors consider may impact their socio-economic wellness.

The relations of influence within the constructed maps was converted into a list of actions and in a Hierarchical Values Structure, incorporating the preferences of the decision-maker. This allowed a structured analysis of the most important dimensions for the stakeholders. The final 1-day workshop permitted us to elicit preferences on the hierarchical tree, depicting the three pillars of sustainable fisheries activities; "strengthening the capacities of processing and marketing," "marine natural resources and opportunities for tourism," and "raising awareness of environmental and socio-economic impacts." Fishermen and other related stakeholders have different preferences about the adoption of diversification strategies, depending on their personal or group goals. Environmental issues or market limitations also influence their willingness to seize opportunities and translate them into concrete actions.
Finally, the hierarchy of stakeholder preferences in various aspects of diversification were expressed using the Analytic Hierarchy Process (AHP) method, a multi-criteria decision-making technique (Saaty, 1970). AHP creates a hierarchy of an individual's preferences considering both quantitative/monetary benefits and qualitative/value judgements. The method is then used to convert individual preferences into ratio-scale weights using structuring, measuring and synthesis.

Following previous studies, our model was constructed by creating a hierarchy. At the top of the hierarchy is the decision goal, followed by the alternatives for reaching the decision, and finally the criteria for evaluating the alternatives. The ranking of the action was constructed by applying the AHP method, which involves deconstructing the decision to be made into a hierarchy of sub-problems, which can then be analysed independently.

Diversification activities (alternatives) were put at the bottom of the hierarchy and were called child elements. Weights were assigned to each element based on stakeholders' votes. The eliciting process produced an extensive range of options for responding to changing conditions that reduces the profitability of fishery activity, which were then screened for clusters of responses of activities diversification strategies.

Once the hierarchy was built, the criteria weights for strategy identification were calculated using Superdecison-Decision Support Software. It guides in judging, via pair-wise comparisons, the relative importance of the objectives and the preference for the alternatives that have been defined (Baby, 2013). During the workshop this procedure was implemented through interactive exchanges of opinion on major challenges and concerns with the stakeholders interviewed. They were asked to express a fundamental point of view that could promote the diversification of fishery activities. The AHP converts these evaluations into numerical values that can be processed and compared over the entire range of the problem. A numerical weight or priority is derived for each element of the hierarchy, allowing diverse and often incommensurable elements to be compared to one another in a consistent way. 
Graphic 1 - Stakeholder preferences in each diversification alternatives.

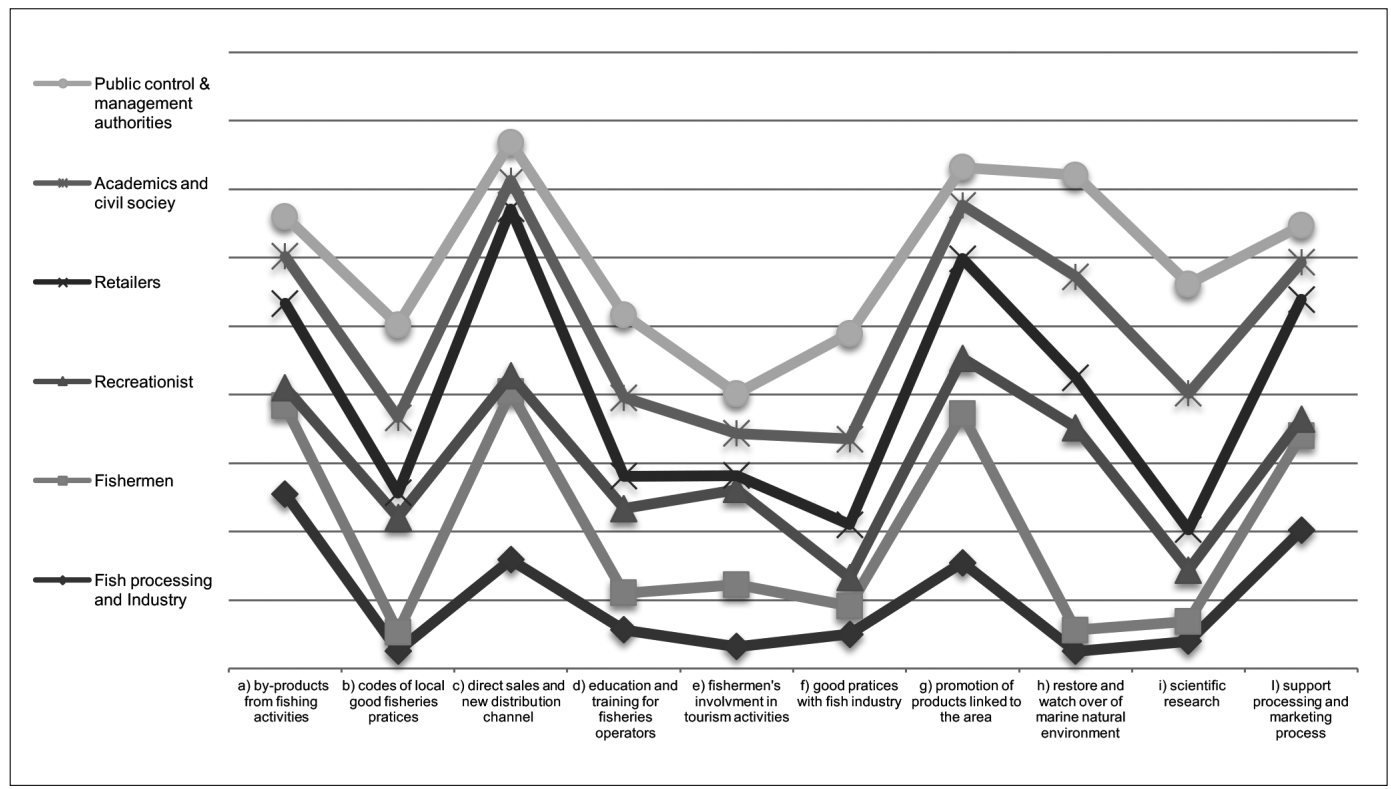

Source: our elaboration.

Graphic 2 - Overall priority.

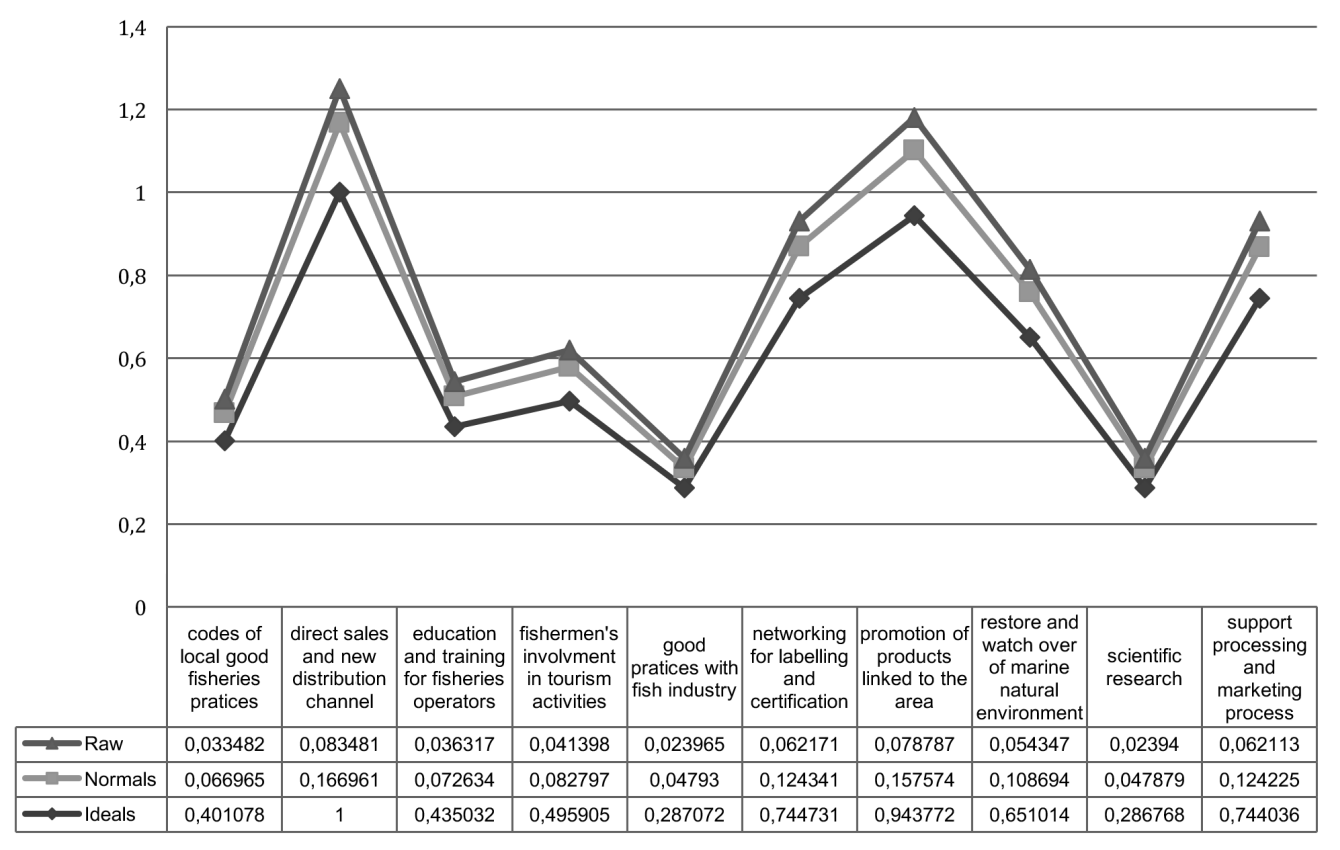

Source: our elaboration. 
Stakeholders compared the factors and judged the comparison as equal, moderate, strong, very strong or extreme.

Participants were asked to compare the two criteria and give a numerical value of 1 to 9 to their relative importance with 1 indicating that the criteria have equal importance and 9 indicating that one criterion is much more important than the other. The process was repeated for all the parent/children sets of nodes with each child element being compared to its corresponding parent element from the same cluster.

\section{Results}

The approach described in this paper has involved stakeholders in a decision-making process that was characterized by high heterogeneity of social agents and stakes, allowing us to identify their preferences and choices regarding fishery diversification strategies. The stakeholders' preferences are represented in Graphic 1. Different types of diversification were detected and subsequently classified into three setting: the field of tourism (such as fishing tourism, sport tourism, itti-tourism, pleasure fishing), the field of products processing and selling (fish processing, tasting locally, direct selling to consumers and fishmongers) and the field of eco-activities (such as environmental monitoring, waste collecting, watch over sea environment).

The results show that the "Direct sales and new organizations of distribution channels" is the best preferred action among diversification fishery activities considered. The other relevant activities are "Networking for developing marketing and business strategies," "Sustainable seafood products labelling and certification," and "Adding value by processing of seafood products," indicating these activities as the most relevant for the stakeholders.

We first note that all stakeholders express different score in all ten alternatives. The analysis of the results shows a polarization of the answers concentrated in different categories of actions, which are related to the specific interests of the stakeholders involved in the research. Fish processing, fishermen, retailers, and academics and civil society always give a significantly higher score than other stakeholders to alternatives aimed at strengthening the capacities of processing and marketing. Recreationist are more interested in measures aimed at maintaining marine natural resources and developing opportunities for tourism, but also directed at raising awareness of environmental and socio-economic impacts. Academics and civil society focus on the development of benefits from partnership with scientific and technical bodies, and fisheries practices for a sustainable protection of cultural heritage in the coastal areas.

Finally, Public control \& management authorities give more importance to different areas of diversification activities, with the highest importance to "Benefits from partnership with scientific and technical bodies," "Training and lifelong learning for fishermen and their families" and "Broaden territorial initiatives concerned with the viability of local fisheries."

According to the results, "Fish processing and industry" and the need to promote and provide "certification and local brands" for traditional fisheries products are considered the activities more feasible for increasing the revenues of fishers through the diversification. They express that the differentiation of fish products by means of innovation and processing, exploitation of by-products, improving the appearance and packaging of products and labelling, can meet the new demand of consumers. Direct selling by fishermen at ports often increases the tourist appeal of these areas and can be part of a wider integrated territorial development initiative. In this regard it is crucial support and promote investment in the diversification of fisheries in terms of the marketing and processing of local fish products, and to boost the development of local distribution channels. However, product differentiation necessitates a suitable promotion and the implementation of appropriated strategies for the target group of fishermen, including cross-border promotional initiatives such as launching joint marketing campaigns with other destinations in the same region and promoting joint marketing platforms.

Touristic services are, in particular directly and indirectly linked to small-scale fisheries, for the direct supply of fish products and for the indirect attraction on visitors. Thus, small- 
scale fisheries may represent a key node for the creation of added value in coastal areas and, the same fishermen can take advantage of a larger share of this value chain through diversification, transformation, direct sale, and cooperation.

Fisheries-related tourism activities, such as eco-tourism can increase knowledge and awareness of the need for environmental protection and cultural conservation. In particular, fishing tours and tourist services offered by fishermen ashore may be a genuine way of supplementing, and diversifying out of, the core activity.

Environment and green economy, including environmental protection, clean-up services, combating pollution and renewable energies are relevant activities in order to limit the indirect impacts of fishing on the maritime environment and to enhance a sustainable diversification of fisheries activities. Combating environmental hazards of a smaller scale is crucial for sustainable fisheries and can also present new or additional activities for fishermen. Water quality is a fundamental concern for fisheries and fish farms as well as a prerequisite for any area expecting to use its waters for tourism purposes.

All the results emphasise the need to raise awareness among local small scale fishermen and to establish synergies among marketing initiatives for high-quality fresh or processed products, gastronomy and tourism, grouped into territorial areas coherent from a cultural, production-related or environmental point of view.

\section{Discussion and conclusion}

The analysis of the results suggests that diversification of fishery activities is a valid option to make small-scale fishing more sustainable. They contribute in increasing income and well-being in the context of small-scale fisheries, thus providing a flexible and adaptive, socially-inclusive model which empowers local stakeholders (Rey-Valette et al., 2017). Diversification of fishery measures cannot be implemented without evaluating the interest and motivation of the communities in the programme. Insight on community point of view is particularly relevant in the understanding of potential capabilities and utilities of diversification strategies, which is one of the cornerstones of Community Led Local Development (CLLD) of EU policy (Salas and Gaertner, 2004).

However, the enhancement of diversification activities needs an integrated strategy. This is crucial especially for small-scale fishery enterprises, where the production flow of each boat is generally low and discontinuous, and the product is highly perishable and cannot be either standardized or differentiated (Malorgio et al., 2017). Aggregation and cooperation are then required to reach an adequate volume and control on supply, allowing cost reduction, supply chain synergies, product differentiation and sales policy that will ensure a more profitable placement of local products. Different forms of horizontal and vertical cooperation, and broader partnerships with public authorities, civic society and enterprises can be strategic for fishermen to address management and marketing issues, but also enhance quality of life.

Therefore, targeted action by regional and local authorities, industry and other stakeholders in coherence with EU policies that have an impact on this sector are needed. Stakeholder dialogue and cooperation such as partnership, networks and clusters should be promoted.

Local strategies for an integrated development of coastal areas should imply the active participation of partnerships including public and private actors. Fishermen are the key actors in this process, and an empowering strategy is necessary to develop their propositional potential in economic and social themes. Bottom-up approach takes the needs of participants into consideration and ensure that the results of diversification activities meet their expectations. However, the development of coastal areas cannot be exclusively left to local initiatives and additional measures are needed to link fishery with other activities in coastal Mediterranean areas.

The participatory approach adopted to explore the potential of the adoption of fishery diversification strategy has provided very useful insight to voiced fishermen and other different stakeholder's opinions and concerns about the options surfaced. This discussion gave rise to agreements regarding actions to be implemented. 
Finally, all participants indicated that they had learned both from each other and from the project, and that this learning was a key trigger for the individuation of specific actions that can be suggested to the policy makers.

To summarize, the following evaluation themes regarding the DiverSo project intervention were derived from the analysis: effective problem structuring process, highly participatory process, mutual learning and shared understanding. The evidence suggests that the high level of commitment to the joint agreements reached by all the partners can be interpreted as indicative of the creation diversification although in itself is not adequate to improve the sustainability of fisheries in the Mediterranean Coast and an additional work effort may be substantial. Therefore, a dialogue among stakeholders is vital to ensure that the results of diversification activities meet expectations of fishers in Mediterranean coastal communities.

\section{Acknowledgements}

This research was conducted within the framework of the research project "Valutazione della sostenibilità dei sistemi agroalimentari locali" WP4, financially supported by the University of Catania and the Department of Fishery of the Regional Sicilian Council. We thank all the stakeholders and workshop participants for their active collaboration.

\section{References}

Aanesen M., Armstrong C.W., Bloomfield H.J., Röckmann C., 2014. What does stakeholder involvement mean for fisheries management? Ecology and Society, 19(4): 35 .

Ackermann F., Eden C., 2004. Using Causal Mapping: Individual and Group, Traditional and New. In: Pidd M. (ed.), Systems Modeling: Theory and Practice. Chichester: Wiley, pp. 127-145.

Baby S., 2013. AHP Modeling for Multicriteria Decision-Making and to Optimise Strategies for Protecting Coastal Landscape Resources. International Journal of Innovation, Management and Technology, 4(2): 218-227.

Belton V., Stewart T.J., 2002. Multiple Criteria Decision Analysis: An Integrated Approach. Boston, MA: Kluwer Academic Publishers.
Bryson J., Ackermann F., Eden C., Finn C., 1995. Using the 'Oval Mapping Process' to identify Strategic Issues and Formulate Effective Strategies, in: Bryson, J. M. (ed.), Strategic Planning for Public and Nonprofit Organizations. San Francisco: Jossey-Bass.

Bryson J., Ackermann F., Eden C., Finn C., 2004. Visible Thinking: Unlocking Causal Mapping for Practical Business Results. Chichester: Wiley.

Carrà G., Peri I., Vindigni G., 2014. Diversification strategies for sustaining small-scale fisheries activity: A multidimensional integrated approach. Rivista di studi sulla sostenibilità, 1: 79-99.

Checkland P., 1978. The Origins and Nature of 'Hard' Systems Thinking. Journal of Applied Systems Analysis. 5: 99-110.

de Vos B.I., van Tatenhove J.P.M., 2011. Trust relationships between fishers and government: new challenges for the co-management arrangements in the Dutch flatfish industry. Marine Policy, 35: 218-225.

Degnbol P., Gislason H., Hanna S., Jentoft S., Nielsen J.R., Sverdrup-Jensen S., Clyde Wilson D., 2006. Painting the floor with a hammer: technical fixes in fisheries management. Marine Policy 30: 534-543.

Eden C., Ackermann F., 1992. Strategy development and implementation - the role of a group decision support system. In: Holtham C., Executive Information Systems and Strategic Decision Support. Uxbridge, UK: Unicom, pp. 53-77.

Eden C., Ackermann F., 1998. Making Strategy: The Journey of Strategic Management. London: Sage.

Ferreira F.A., Santos S.P., Rodrigues P.M., 2011. Adding value to bank branch performance evaluation using cognitive maps and MCDA: a case study. Journal of the Operational Research Society, 62(7): 1320-1333.

Franco L.A., Montibeller G., 2010. Facilitated modelling in operational research. European Journal of Operational Research, 205(3): 489-500.

Funtowicz S.O., Ravetz J.R., 1993. Science for the post-normal age. Futures, 25: 739-755.

Haapasaari P., Mäntyniemi S., Kuikka S., 2013. Involving stakeholders in building integrated fisheries models using Bayesian methods. Environmental Management, 51(6): 1247-1261.

Hodgkin J., Belton V., Koulouri A., 2005. Supporting the intelligent MCDA user: A case study in multi-person multi-criteria decision support. European Journal of Operational Research, 160(1): 172-189.

Jahn T., Bergmann M., Keil F., 2012. Transdisciplinarity: between mainstreaming and marginalization, Ecological Economics, 79: 1-10. 
Kelly G., 1955. The Psychology of Personal Constructs. New York: Norton \& Company.

Kelly G., 1970. A brief introduction to personal construct theory. London: Academic Press.

Kpoumié A., Damart S., Tsoukiàs A., 2017. Integrating cognitive mapping analysis into multi-criteria decision aiding. https://hal.archives-ouvertes.fr/ hal-01510937.

Linke S., Dreyer M., Sellke P., 2011. The Regional Advisory Councils: what is their potential to incorporate stakeholder knowledge into fisheries governance? AMBIO, 40: 133-143.

Malorgio G., Mulazzani L., Pugliese P., Rota C., Zanasi C., Zuccaro M., 2017. The role of small-scale fisheries in Mediterranean coastal communities. An analytical framework for their development. New Medit, XVI(2): 19-26.

Midgley G., 1997. Mixing methods: developing systemic intervention. In: Mingers J., Gill A. (eds.), Multimethodology: the theory and practice of combining management science methodologies. Chichester: Wiley, pp. 249-290.

Montibeller G., Franco A., 2010. Multi-Criteria Decision Analysis for Strategic Decision Making. In: Zopounidis C., Pardalos P. (eds.), Handbook of Multicriteria Analysis. Applied Optimization. Berlin, Heidelberg: Springer.

Munda G., 2004. Social Multi-Criteria Evaluation: Methodological Foundations and Operational Consequences. European Journal of Operational Research, 158(3): 662-677.

Rey-Valette H., Mathé S., Salles J.M., 2017. An assessment method of ecosystem services based on stakeholders perceptions: The Rapid Ecosystem
Services Participatory Appraisal (RESPA). Ecosystem Services, 28: 311-319.

Röckmann C., Ulrich C., Dreyer M., Bell E., Borodzicz E., Haapasaari P., Hauge K.H., Howell D., Mäntyniemi S., Miller D., Pastoors M., 2012. The added value of participatory modelling in fisheries management - what has been learnt? Marine Policy, 36: 1072-1085.

Rosenhead J., Mingers J., 2001. A New Paradigma of Analysis. In: Rosenhead J., Mingers J. (eds.), $R a-$ tional Analysis for a Problematic World Revisited: Problem Structuring Methods for Complexity, Uncertainty and Conflict, Second Edition. Chichester: John Wiley \& Sons, pp. 1-19.

Roy B., 1985. Méthodologie multicritère d'aide à la décision. Paris: Economica.

Roy B., 1990. Decision aid and decision making. In: Bana e Costa C.A. (ed.), Readings in multiple criteria decision aid. Heidelberg: Springer-Verlag, pp. 17-35.

Saaty T.L., 1970. How to Make a Decision: The Analytic Hierarchy Process. European Journal of Operational Research. 48: 9-26.

Salas S., Gaertner D., 2004. The behavioral dynamics of fishers: management implications. Fish and Fisheries, 5(2): 153-167.

Tsoukias A., Montibeller G., Lucertini G., Belton V., 2013. Policy Analytics: an agenda for research and practice. EURO Journal on Decision Processes, 1: 115-134.

Wiber M., Berkes F., Charlesc A., Kearney J., 2004. Participatory research supporting community-based fishery management. Marine Policy, 28: 459-468.

Ziman J., 1996. Is science losing its objectivity? $\mathrm{Na}$ ture, 382: 751-754. 